\title{
Leadership in a Diversified Culture: Qualitative Perspective
}

\author{
Mansour S. M. Lotayif ${ }^{1}$ \\ ${ }^{1}$ Applied Science University (ASU) Bahrain, Kingdom of Bahrain \\ Correspondence: Mansour S. M. Lotayif, Applied Science University (ASU) Bahrain, Building 166, Road 23, \\ Block 623, East Al-Ekir, Kingdom of Bahrain. E-mail: Mansour.lotayif@asu.edu.bh
}

Received: November 8, 2020

Accepted: December 10, 2020

Online Published: December 28, 2020

doi:10.5539/ijbm.v16n1p110

URL: https://doi.org/10.5539/ijbm.v16n1p110

\begin{abstract}
The current article addresses the leadership in higher education institutions (HEIs) with diversified cultures' academics. It stresses the importance of leadership in academia by presenting a self-experience case in this perspective. The experience of 100 academics were utilized, via one-to-one interview, in this perspective in answer two research questions i.e. "how to deal appropriately with a much diversified work culture" and "how to exercise leadership traits in a diversified higher education context?
\end{abstract}

Keywords: Leadership, diversified cultures, and higher education institutions (HEIs)

\section{Introduction}

In higher education institutions and by adopting the system approach, the inputs are represented by manpower, management, materials, money, and machines (5M's) are utilized to build the capabilities and competitive advantages. Manpower is crucial in service industry in general, and in education industry in particular. The interaction between service provider i.e. the instructor and the students' shapes, to large extent, the level of delivered quality. Consequently, developing the leading skills required for each instructor could be considered the vital competitive advantage in this industry. Therefore, the current study seeks answer for two questions, which are "how to deal appropriately with a much diversified work culture" and "how to exercise leadership traits in a diversified higher education context? Therefore, the related literature of leadership in HEIs is examined in this perspective then presenting a real leading case in Kingdom of Bahrain context.

\section{Literature Review}

To lead in any work you have to have leadership skills. To be visionary i.e. to visualize your career and institution after a period from now, and to have your own way in dealing with subordinates to achieve that vision are two main skills of today's leaders (Northouse, 2013). Skills could be classified to technical, human, and conceptual. Technical skill to be familiar of work steps, rules, and policies to perform professionally. Human skill focuses on understanding others and to be understood besides how to lead your team appropriately. Conceptual skill focuses on the ability to visualize the organization as one system contains many subsystems and the relationships amongst these subsystems besides critical thinking skills (Northouse, 2013; Yukl 2006; and Katz 1974). In Higher Education Institutions (HEIs) context, the leader ought to possess emotional intelligence (EI) which means the ability to lead change and work with team members effectively. Goleman $(1995,1998)$ argued that EI includes empathy, motivation, self-regulation, and self-awareness. Fullan (2011) added that building strong relationships with staff, faculty, students and other stakeholders especially in times of crisis e.g. COVID-19 are the main crucial leader' skills. Levy and Beaulieu (2003) added that effective leader ought to be familiar of pedagogical policies like student services bylaw, staff training and support, and student training and support. Strategic planning literature figures out the sequential steps to be followed in this perspective. It starts by determining vision, mission, objectives, strategies, policies, procedures, rules, budget, and programs. Consequently, learning, and assessing (TLA) policy should align with university vision, mission, objectives, and strategies to be implemented appropriately.

Recently and in leading team members, a new terminology emerged called "distributed leadership" (Jitse et al., 2009). Angela et al., (2017) claimed that distributed leadership would promote and advance excellence in learning and teaching in HEIs. In leadership literature, some scholars are using the term "shared leadership" (e.g., Pearce, 2004; Pearce \& Sims, 2002) while others are using the term "distributed leadership" (e.g., Gronn 2002). In addition, a third stream using "shared and distributed" terminologies interchangeably (e.g., Day et al. 2004). Therefore, 
leadership could be viewed as "shared or distributed" phenomena. Therefore, each team member could participate in leadership within his/her own team. However, distributed leadership does not dismiss hierarchical structures with lines of commands (Angela et al., 2017). Cummings and Worley (2004) argued about reason for that shift in leadership literature. It could be due to increase reliance on teamwork rather than leader-centric approaches. This distributed leadership consists of three main elements: (1) Concretive action, (2) An openness of boundaries, and Breadth and depth of expertise (Bolden et al., 2009; Harris, 2005; Woods, Bennett, Harvey, \& Wise, 2004; Gronn, 2002). Concretive action means pool out and utilize the expertise and initiative of each team member to enhance team's performance. This action leads to make team performance greater than the sum of team member's performances. An openness of boundaries means open up the level of discussion amongst team members. Breadth and depth of expertise means distributing this expertise across all team members regardless their position in the formal hierarchy of the organization i.e. all are equal. Meanwhile, traditional leadership theories (i.e. situational leadership, charismatic leadership, transformational, and leader-member exchange) that favor and centered on the formal structures and lines of authority still in practice in higher education (Aldulaimi,2018; Bass, 1998; Graen \& Uhl-Bien, 1998; Graeff, 1997; Conger; 1989; Brass, 1984; Burns; 1978; and Vroom \& Yetton, 1973).

In academia like in any other businesses, there is self-leading and non-self-leading staff members. Jooste et al., (2015) differentiate between self-leading individual and non-self-leading one. Self-leading individuals demonstrate higher levels of commitment to their goals, teams, tasks, or organizations compared with individuals who do not engage in self-leadership mechanism. Self-leadership of academics means to exercise high level of inner motivation for oneself to reach the highest possible level of performance. It worth mentioning that such study is a pioneer one in this area of the globe especially for higher education context.

The questions that could rise here are "how to deal appropriately with a much diversified work culture" and "how to exercise leadership traits in a diversified higher education context?" Then, the collected data will be used to seek answer for these two questions.

\subsection{Study Objectives}

The current study seeking answer for the following two questions:

1-How to deal appropriately with diversified work culture?

2-How to exercise leadership traits in a diversified higher education context?

\section{Study Methodology}

The qualitative approach was used in the current study. The experience of 100 staff members in a Bahraini university i.e. AMA university in Bahrain were utilized to answer research questions. One-to-one unstructured interview was used as a data collection tool in this perspective. Case study representing one Bahraini university was utilized in the current study to get deep and concentrated insights in this perspective.

\section{Analysis and Discussions}

The data collected was utilized to reach clear understanding of academic environment in Bahraini HEIs context and to seek answers for research questions. Generally, to lead in organizations with diversified cultures is not an easy task at all. In AMA University in Bahrain (one Bahraini university), the staff members' routs are highly diversified as they came from different corners in the globe. The main portion came with Fareast culture, mainly Philippines. Another part came with Arabic culture backgrounds i.e. Egyptian, Jordanians, Iraqis, Algerians, Bahrainis, etc. A third part came with western culture like British, Australian, and American. A forth part came with Asian cultures like Indians, Pakistanis, and Bangladeshis. The last portion came with African cultures like Nigeria, South Africa, Senegal, and Sudan. Since joined at 2016, the AMA University was preparing for three accreditations: (1) accreditation from European Council for Business Education (ECBE); (2) quality accreditation from Bahraini Higher Education Council (HEC); and (3) institutional listing for BQF (Bahraini Qualifications Framework).

All university resources allocated and directed toward the successful achievement of these three accreditations. My leadership roles in this mission were: (1) As specialized coordination of marketing and international business domains with the responsibility for adjusting all taught curriculums and TLA (Teaching, Learning, and Assessment) policy to be aligned with ECBE, QA, and BQF. (2) As I was the highest ranked staff member in CAFS (College of Administrative \& Financial Studies) with professor title, I participated and headed the three consecutive defense panels. (3) As informal MBA coordinator (after I rejected to be formal coordinator) with full responsibility for exam process at university Auditorium. (4) With the strategic planning team members, I participated in checking the recommendations revealed from the "Focus Study" that conducted via subcontractor for exploring and determining the needs of target markets. (5) With my team members, the academic "Areas and Standards", that 
related to running the university academically and administratively, were checked and their key indicators (KIs) for implementation control were verified and redesigned. In the following lines, I will explain these five leadership roles in that diversified culture.

(1) In specialized coordinator role, I conducted induction seminars and workshops to pave the way for these three accreditations with relevant staff members to align delivered courses and their course specifications with accreditation criteria. In these seminars, softy-softy leading strategy with multiculturalism has been followed. Multiculturalism is a tool, a medium, and a way to promote or inculcate harmony, peace and respect toward the other beliefs, customs, and religions (Bank 2007). The adopted leadership strategy aimed at spreading the understanding and respect of Bahraini culture, believes, values, traditions, customs, and national identity. In addition, to make each staff member more tolerant by developing a sense of belonging toward the local community and to humankind at large (Rizvi, 1993). Annex, in all meetings I headed for that mission, I was keen in stressing intercultural competence (IC). Bank, (2007) have explained IC as the capability to interact or communicate appropriately and in effective manner with the people from other cultures, norms, and believes to build a strong inner ties and relationships.

More specifically, local, regional, and international informal (i.e. website and online without legal contract) benchmarking sessions were held to refining the course specifications to align with QA, NQF, and ECBE. The outcomes were redesign the learning activities and their related TLA policy and restructuring the whole programs at large. To achieve that mission, rounds and series of meeting held in this perspective. In these meetings, I was keen to respect each staff member's culture to ignite the creativity engine and motivate for maximum outcomes. Arshad, (2017) defined culture as a system and body of accumulated knowledges that helps understand communication patterns in different cultures i.e. what is allowed what is forbidden.

(2) The leading roles in defense panels. We did rounds of preparations, rehearsals and mock-presentations to prepare defense team's members for that mission. I designed a SWOT analysis highlighting the programs pros and cons from inside sources, and I stressed the opportunities and threats urging for change from outside forces. In presentations, rehearsals and mock-presentations, I stressed the pros and suggested recipe for rectifying related policies for cons. The contributions in that stage were adding up fresh and updated teaching materials coupled with their relevant assessing tools. For instance, the suggested weekly training session for all staff members that approved by management, was one of the interesting outcomes at that stage.

(3) Informal MBA coordinator with exam hall full responsibility. To ensure fair opportunities in assessing students' skills and competencies and enhancing the quality of graduates, I was responsible for leading the exam invigilation process from allocating appropriate sets for each staff member's students to implement exam instructions for preventing cheating and misconduct.

(4) Focus study recommendations' role. After completed via a subcontractor consultant, focus study consequences and ramifications were considered in program restructuring stage. Islamic Finance and Banking, Entrepreneurship, and Sustainable Development modules coupled with their relevant TLA policy and pedagogy technologies have added to the current courses. Benchmarking sessions were conducted for creating course specifications for these fresh courses.

Finally, areas and standards mapping role. I was part of the team responsible for area two i.e. academic management and administration with its 4 standards. These standards were "the institution must be effectively managed", "academic management must be effective", "the institution must be effectively administered", and "the institution must employ appropriately qualified and experienced managerial, administrative and technical staff" that measured by 17, 7, 7, and 10 key indicators (KIs) respectively. To share the knowledge and thoughts related to checking and ensuring the existence of these standards and their KIs, part of team members' communications was face-to-face and another part conducted virtually, as virtual teams are becoming a basic work-unit in the information era nowadays. Virtual teams are heavy reliance on information communication technologies (ICT) as communication tools linking their members (Lipnack and Stamps, 1997). Normally, ICT links, in virtual teams, could be either synchronous or asynchronous ways used to carry out interpersonal communication, collaboration and coordination (O'Hara-Devereaux and Johansen, 1994). Chen et al., (2008) clarified the differences between synchronous and asynchronous. As synchronous ICT tools vary in terms of social presence, and information richness, and could be classified as text, audio, and video-conferencing systems. While, asynchronous ICT tools range from e-mails, discussion forms, and bulletin boards, to workflow, scheduling and other project management applications.

Asynchronous ICT links like emails, flowcharts, and Gantt-chart were used in checking the effectiveness of running the AMA University. Here, I participated in checking the qualifications status quo of senior executives to 
figure out the level of matching between staff qualifications and experiences and the occupied positions to ensure sound academic environment. In addition, I participated in checking the university organizational structure's levels and documentations to ensure its understanding by the surrounding stakeholders, especially students. Annex I did participate in ensuring the existence of academic job descriptions with clear authorities and responsibilities, and in ensuring the existence of the appropriate documentations process and archiving systems for university academic meetings and committees to help enhance the academic environment.

In addition, I participated in checking the soundness and effectiveness of academic process. As, I participated in checking the accreditation status-quo of CAFS. In this mission, my role was to assure that all delivered programs have to have accreditation from BQF and NAQQAET (National Authority of Qualifications and Quality Assurance for Education and Training). Moreover, to ensure enhancing the quality of teaching process, the AMA University TLA was refined to ensure the clear mapping between learning outcomes and adopted teaching methods. Annex, I participated in checking the policy' criteria for appointing and promotion to ensure fairness and help enhance the academic quality.

In effectiveness assurance, I participated at enhancing the quality of the university backyard (i.e. internal customers or employees) by assuring the availability and sufficient qualified administrators and the existence of related policies and procedures to enhance academic quality. Finally, I participated at checking the promotion and recruiting policies to ensure the balance between academic and non-academic ratio.

\section{Conclusion}

The current study clarify the appropriate way in dealing with diversified work culture and explained how to exercise leadership traits in that diversified work culture in Bahraini higher education context. Therefore, the gained experience from this case help enhance the quality of teaching and researching practices, as the richness of that diversified culture positively fueled each staff member expertise, skills, and communication patterns. Therefore, I am urging HEIs to extend their hiring strategy to include diversified staff members to enjoy the beauty of each culture.

\section{References}

Aldulaimi, S. H. (2018). Leadership development program and leaders performance for mid-level managers in Saudi Petroleum Company, ARAMCO. Arab Economic and Business Journal, 13(1), 15-24. https://doi.org/10.1016/j.aebj.2018.02.001

Angela, C., Julia, E., Bella, R., Steve, D., Liam, P., Katherine, L., Caroline, C., Susan, S., \& Jing, Y. (2017). Assessing distributed leadership for learning and teaching quality: a multi-institutional study. Journal of Higher Education Policy and Management, 183-196. https://doi.org/10.1080/1360080X.2017.1276629

Arshad, S. (2017). University Leaders' Perceptions and Contextual Realities for Encouraging Intercultural and Multicultural Harmony in Higher Education Institutions Sindh- Pakistan. Journal of Social Sciences, 11(2), 214-226.

Bank, J. A. (2007). Educating Citizens in a Multicultural Society (2nd ed.). New York: Teachers College Press.

Bass, B. M. (1998). Transformational leadership: Industrial, military, and educational impact. Mahwah, New Jersey: Lawrence Erlbaum Associates Inc.

Bolden, R., Petrov, G., \& Gosling, J. (2009). Distributed leadership in higher education: Rhetoric and reality. Educational Management Administration \& Leadership, 37(2), 257-277. https://doi.org/10.1177/1741143208100301

Brass, D. J. (1984). Being in the right place: A structural analysis of individual influence in an Organization. Administrative Science Quarterly, 29(4), 518-539. https://doi.org/10.2307/2392937

Burns, J. M. (1978). Leadership. NY: Harper \& Row.

Chen, C. C., Wu, J., Yang, S. C., \& Tsou, H.-Y. (2008). Importance of Diversified Leadership Roles in Improving Team Effectiveness in a Virtual Collaboration Learning Environment. Educational, Technology and Society, 11(1), 304-321.

Conger, J. (1989). The charismatic leader: Behind the mystique of exceptional leadership. San Francisco, CA: Jossey-Bass.

Cummings, T. G., \& Worley, C. G. (2004). Organization development and change. OH: South-Western.

Day, D. V., Gronn, P., \& Salas, E. (2004). Leadership capacity in teams. The Leadership Quarterly, 15, 857-880. 
https://doi.org/10.1016/j.leaqua.2004.09.001

Day, D. V., Gronn, P., \& Salas, E. (2004). Leadership capacity in teams. The Leadership Quarterly, 15, 857-880. https://doi.org/10.1016/j.leaqua.2004.09.001

Fullan, M. (2011). The Six Secrets of Change: What the best leaders do to help their organizations survive and thrive. San Francisco, CA: Jossey-Bass.

Goleman, D. (1995). Emotional Intelligence. New York, NY: Bantam.

Goleman, D. (1998). Working with Emotional Intelligence. New York, NY: https://doi.org/10.1002/lt1.40619981008

Graeff, C. L. (1997). Evolution of situational leadership theory: A critical review. The Leadership Quarterly, 8(2), 153-170. https://doi.org/10.1016/S1048-9843(97)90014-X

Graen, G. B., \& Uhl-Bien, M. (1998). Relationship-based approach to leadership: development of leader-member exchange (LMX) theory of leadership over 25 years: Applying a multi-level Multi-domain perspective. In F. Dansereau \& F. J. Yammarino (Eds.), Leadership: The multiplelevel approaches: Contemporary and alternative (Part B Vol. 24, pp. 103-155). USA: Elsevier Science/JAI Press.

Gronn, P. (2002). Distributed leadership as a unit of analysis. The Leadership Quarterly, 13, 423-451. https://doi.org/10.1016/S1048-9843(02)00120-0

Harris, A. (2005). OP-ED. Journal of Curriculum Studies, 37(3), 255-265. https://doi.org/10.1080/00220270500038602

Jitse D. J., Van, A., Patrick, C. N., Jon, B., \& Nathalie, V. M. (2009). Improving leadership in Higher Education institutions: a distributed perspective. Higher Education, 58, 763-779. https://doi.org/10.1007/s10734-0099224-y

Jooste, K., Ahanohuo, L., \& Arunachallam, S. (2015). The meaning of self-leadership for nursing academics of a research programme in the context of a higher education institution in the Western Cape. Afr J Nurs Midwifery, 17(1), 122-133. https://doi.org/10.25159/2520-5293/238

Katz, R. L. (1974). Skills of an effective administrator. Harvard Business Review, 52(5), 90-102.

Levy, S., \& Beaulieu, R. (2003). Online distance learning among the California Community Colleges: Looking at the planning and implementation. American Journal of Distance Education, 17(4), 207-220. https://doi.org/10.1207/s15389286ajde1704_2

Lipnack, J., \& Stamps, J. (1997). Virtual Teams: Reaching Across Space, Time and Organization with Technology. New York: John Wiley \& Sons.

Northouse, P. G. (2013). Leadership: Theory and practice (6th ed.). Thousand Oaks, CA: Sage.

O'Hara-Devereaux, M., \& Johansen, R. (1994). Global work: Bridging Distance, Culture, and Time. San Francisco, CA: Jossey-Bass.

Pearce, C. L. (2004). The future of leadership: Combining vertical and shared leadership to transform knowledge work. Academy of Management Executive, 19, 47-57. https://doi.org/10.5465/ame.2004.12690298

Pearce, C. L., \& Sims, H. P., Jr. (2002). Vertical versus shared leadership as predictors of the effectiveness of change management teams: An examination of aversive, directive, transactional, transformational, and empowering leader behaviors. Group Dynamics: Theory, Research, and Practice, 6, 172-197. https://doi.org/10.1037/1089-2699.6.2.172

Rizvi, F. (1993). Race, Gender and the Cultural Assumptions of Schooling. In C. Marshall (Ed.), The New Politics of Race and Gender. Bristol, PA: Flamer Press.

Rose, S. (2020). Medical student education in the time of COVID-19. JAMA, 23(21), 2131-2132. https://doi.org/10.1001/jama.2020.5227

Vroom, V. H., \& Yetton, P. W. (1973). Leadership and decision-making (Vol. 110). Pittsburgh, USA: University of Pittsburgh Press. https://doi.org/10.2307/j.ctt6wrc8r

Woods, P. A., Bennett, N., Harvey, J. A., \& Wise, C. (2004). Variabilities and dualities in distributed leadership findings from a systematic literature review. Educational Management Administration \& Leadership, 32(4), 439-457. https://doi.org/10.1177/1741143204046497

Yukl, G. (2006). Leadership in Organizations (6th ed.). Upper Saddle River, NJ: Pearson-Prentice Hall. 


\section{Copyrights}

Copyright for this article is retained by the author(s), with first publication rights granted to the journal.

This is an open-access article distributed under the terms and conditions of the Creative Commons Attribution license (http://creativecommons.org/licenses/by/4.0/). 